\title{
Comparative study of cutting force development during the machining of un-hybridized and hybridized ZA43 based metal matrix composites
}

https://doi.org/10.1515/jmbm-2019-0016

Received Nov 02, 2019; accepted Nov 14, 2019

\begin{abstract}
In the present study, turning of two grades of composites such as ZA43 silicon carbide and ZA43 silicon carbide and graphite was carried out. The fabrication of both categories of composites were done using stir casting technique. The silicon carbide of grit size $60 \mu \mathrm{m}$ with concentration of $5 \%$ was reinforced for one category of the composite and for the other grade of composite, $5 \%$ silicon carbide and graphite were added. Thus fabricated materials were turned on a conventional lathe using coated carbide tools (SNMG). Dry turning of the fabricated composite was carried out with varying cutting parameters. Measurement of cutting force was done for the both compositions of fabricated materials using lathe tool dynamometer. It was observed that, while machining composite containing silicon carbide and graphite, tool experience more cutting force than composite containing silicon carbide alone.
\end{abstract}

Keywords: Hybrid metal matrix composites, turning, coated carbide tool, graphite, cutting force

\section{Introduction}

Aluminium metal matrix composites find wide range of applications in the field of automobile industries, aerospace applications, defence etc. due to their excellent properties such as light weight, high strength, wear resistance, strength - weight ratio, strength to cost ratio and low thermal expansion [1]. A lot of efforts have been made to mix the hard particulates such as $\mathrm{SiC}, \mathrm{Al}_{2} \mathrm{O}_{3}, \mathrm{~B}_{4} \mathrm{C}$ into aluminium based MMCs. Literature survey reveals that, $\mathrm{SiC}$ is the best reinforcement for aluminium based MMCs due

\footnotetext{
${ }^{\star}$ Corresponding Author: K. J. Santhosh Kumar: Dept. of Mechanical Engineering, G M Institute Technology, Davanagere - 577006, Karnataka, India; Email: kjsanthu1991@gmail.com Rajaneesh N. Marigoudar: Dept. of Mechanical Engineering, Jain Institute Technology, Davanagere - 577003, Karnataka, India
}

to its chemical affinity towards the aluminium and forms a good bond with the matrix without developing intermetallic phase. Nowadays, due to increased industrial requirement of engineering materials which are having high strength and high wear resistance, hybrid MMCs are developed $[2,3]$. The main factor that prevents embracing the MMCs is the difficulty in machining them due to high abrasive and intermittent nature of the reinforcements. Generally MMC components are mostly manufactured near to the close dimensions and then machined to the final dimensions and final surface finishes. Conventional tool materials such as high speed steel cannot be used for the machining of MMCs because of the rapid tool wear. Coated or uncoated carbide tools and ceramic tools sustain the tool wear significantly and are best choice for the machining of MMCs [4-7].

Zinc and Aluminium based alloys have very good wear resistance properties which are comparable with properties of cast iron. Commercially available ZA alloy has $27 \%$ of aluminium which has favourable properties. When the presence of aluminium in the alloy increased to $43 \%$, the wear resistance and hardness increases, at the same time fluidity and elasticity decreases. Adding the ceramic particulate particles to such a high wear resistant alloy makes the resultant alloy to have superior wear resistant property [8-11]. Machining such composite with commercially available tool is very difficult because of hard reinforcement. The important factor which influence the tool life is supply of lubrication during the machining process. Instead of applying fluid externally for machining process, solid lubricant is introduced into the matrix during fabrication stage itself so that the friction during machining process get reduced and life span of cutting tool improves. Adding graphite to ZA alloy reduces the tool wear at all working conditions because it offers less coefficient of friction between work piece and tool [12].

In this paper importance is given to analyze the development of cutting force during the machining of MMC. When an alloy alone comes in contact with the cutting tool during the process of machining, forces developed on 
the cutting tool is somewhat predictable. But when the reinforcements embedded in the same alloy come in contact with the tool forces acting on the tool become unpredictable. The soft matrix phase in the matrix deforms plastically easily and show good machinability characteristics, whereas the hard reinforcement phase behaves unnaturally. Many researchers have studied and presented their ideas theoretically and experimentally regarding the cutting force developed while machining these heterogeneous materials.

Anandakrishnan and Mahamani [13] investigated on machinability of $\mathrm{Al}^{6061-\mathrm{TiB}_{2}} \mathrm{MMC}$ fabricated through fluxassisted synthesis. The result shows that higher reinforcement ratio produces higher tool wear, surface roughness and minimizes the cutting forces. Increase in cutting force and the rate of flank wear with depth of cut and feed rate was observed. Paulo Devim $[14,15]$ investigated on machinability of Al-356 reinforced with SiC composite. Dry turning was done using PCD tools. The results of the work show that feed rate affects the surface roughness and cutting speed affects the cutting force.

Manna and Bhattacharya $[16,17]$ worked on machinability characteristics of aluminium MMC reinforced with $\mathrm{SiC}$ particles. Turning was done using rhombic coated and uncoated carbide tools and investigated the effect of feed rate, cutting speed and depth of cut on cutting force was analyzed. The results shows that increase in cutting force with the increase in feed and decrease in cutting speed. Chou [18] worked on the MMC and investigated the effect of speed and feed on cutting force. The results of the study reveal that the cutting force was decreased with increase in cutting speed and increased with increase in feed rate.

Kishway et al. $[19,20]$ investigated on MMC and observed that the linear increase in the cutting force with the feed rate and decrease in cutting force with the cutting speed. Rajaneesh and Sadashivappa [21] analysed the cutting forces developed while machining the MMC using ceramic tool. The results of study reveal that increasing depth of cut, particle size and volume fraction increase the cutting force significantly and increasing cutting speed cause the decrease in cutting force. Suhas Joshi et al. [22, 23] developed a mathematical model in order to determine the cutting forces developed during the machining of aluminium based MMC reinforced with SiC. According to the model, the reinforcement particles present in the MMC are responsible for the variation in values of cutting force during machining. Zhang [24] developed a mathematical model to predict the cutting force and thrust force while machining the $\mathrm{MMC}$ reinforced with hard particulates. The cutting force was considered that it consist of components due to formation of chips, ploughing and particle fracture, and displacement. Merchant's shear plane theory, slip line field theory and Griffith theory were used for the calculation of these components respectively. The study revealed that the cutting force developed due to ploughing and particle fracture is much more less than the cutting force developed due to chip formation. Sikdar [25] proposed the similar type of model to determine the cutting force developed while machining the MMC reinforced with hard particulates by considering particle fracture force, ploughing force and frictional characteristics at tool- chip and toolwork interfaces. The effect of volume fraction of reinforcements in the MMC on cutting force can also be calculated using this model. In this model, only $3 \%$ cutting force and $15 \%$ thrust force variation was observed between the experimental and mathematical values.

Looking at the observations proposed by the various researchers mentioned above, it is clear that there is a lot of scope for the analysis of machinability of MMC reinforced with hard particulates using various types of cutting tools. In this paper, effect of graphite and machining parameters on cutting force development during machining of two different categories of materials was compared.

\section{Materials and testing}

The composition of zinc aluminium matrix alloy is as given in the Table 1.

Both the categories of composites were fabricated by stir casting method. The setup of stir casting is as shown in Figure 1. The weighed amount of metal as per the alloy composition is taken in the crucible and heated above the melting temperature of aluminium till whole mass in

Table 1: Composition of matrix in their weight percentages

\begin{tabular}{ccccc}
\hline Element & $\mathrm{Al}$ & $\mathrm{Cu}$ & $\mathrm{Mg}$ & $\mathrm{Zn}$ \\
\hline Percentage (wt.) & 43 & 2.5 & 0.02 & Rest \\
\hline
\end{tabular}

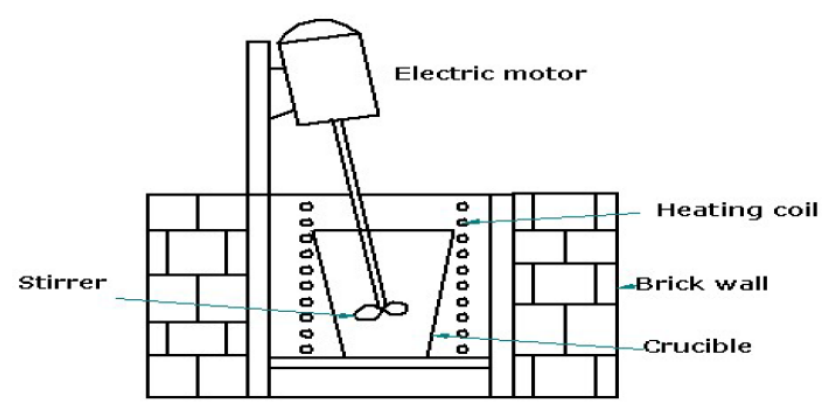

Figure 1: Stir casting mechanism for casting MMC 

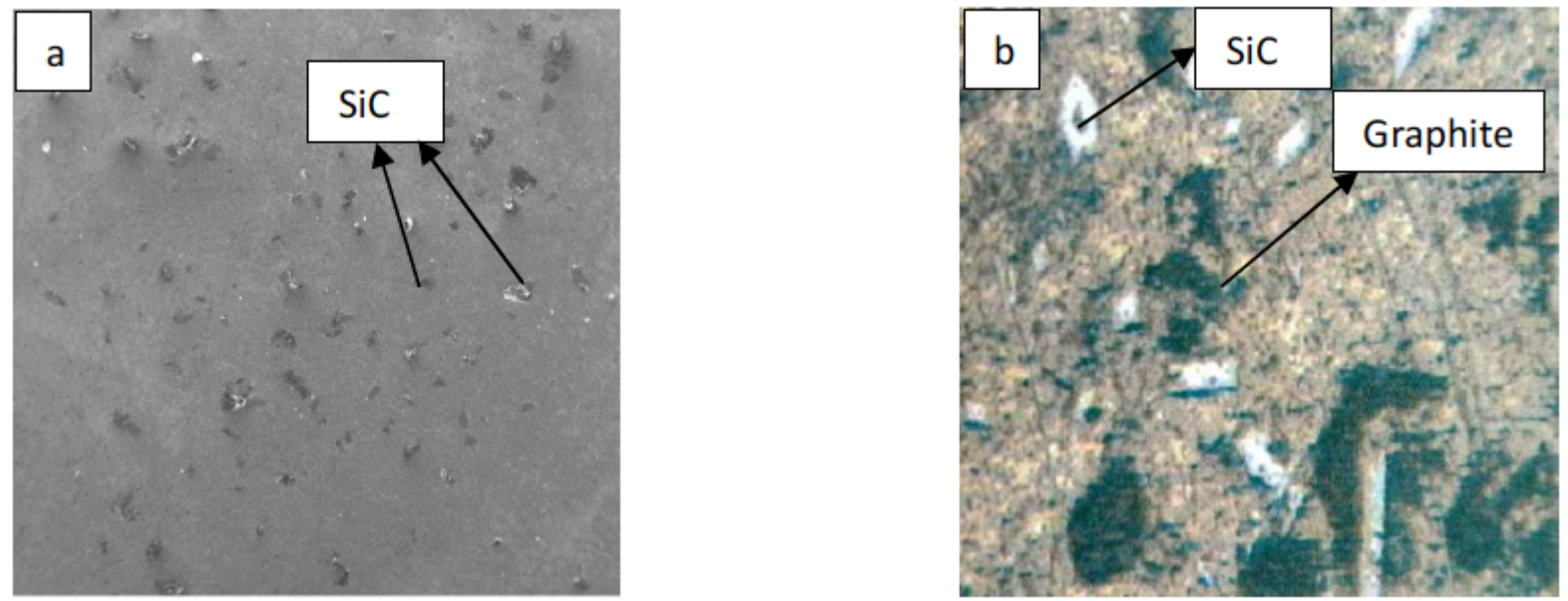

Figure 2: a) SEM image of Un-hybridised MMC b) SEM image of hybridised MMC

Table 2: Cutting tool inserts specifications

Tool specification

Tool image

Coated Tungsten Carbide - SNMG - 090308 (Kennametal WIDIA Tool)

Square insert with $9 \mathrm{~mm} \times 9 \mathrm{~mm}$ square, thickness of $3 \mathrm{~mm}$ and $0.8 \mathrm{~mm}$ corner radius - Normal clearance of $0^{\circ}$ - Tolerance of nose height $\pm 0.08- \pm 0.18$, Tolerance of inscribed circle $\pm 0.05- \pm 0.15$, Tolerance of thickness \pm 0.13 , Double sided chip breaker. Triple layer CVD coated with $\mathrm{Al}_{2} \mathrm{O}_{3}$, TiN and TiCN.

Table 3: Selection of machining parameters and their levels

\begin{tabular}{ccccc}
\hline Parameters & Units & Level 1 & Level 2 & Level 3 \\
\hline Speed & $\mathrm{m} / \mathrm{min}$ & 95 & 125 & 175 \\
Feed & $\mathrm{mm} / \mathrm{rev}$ & 0.05 & 0.1 & 0.15 \\
Depth of cut & $\mathrm{mm}$ & 0.25 & 0.50 & 0.75 \\
\hline
\end{tabular}

the crucible come to liquid phase. To have unhybridized composite, pre heated silicon carbide particles $(60 \mu \mathrm{m}, 5 \%$ by weight) were introduced in to the molten matrix and stirred well using coated stainless steel blade at a speed of around $600 \mathrm{rpm}$. The coating to the stainless blade was done to prevent the diffusion of blade material in to the matrix material. To have hybridized material, to the molten matrix, pre heated silicon carbide $(60 \mu \mathrm{m}, 5 \%$ by weight $)$ and graphite ( $10 \mu \mathrm{m}, 5 \%$ by weight) powder both were introduced and stirred.

The preheating of the $\mathrm{SiC}$ and graphite was done to improve the wettability of the composite. A small percentage of magnesium was added into the liquid metal which will also help to increase the wettability [26, 27]. The stirring was done for the uniform distribution of reinforcing materials in to the molten matrix. Thus stirred mass was transferred to suitable metallic dies and allowed for solidification. Once material attain the room temperature, specimen were removed from the dies and subjected to further testing conditions. The fabricated specimen bear dimensions with $300 \mathrm{~mm}$ length and $54 \mathrm{~mm}$ diameter.

Microscopic study of the MMCs was carried out using Scanning Electron Microscope (SEM) to know the distribution of the reinforcing particles in the matrix. SEM images of the composites are shown in Figure 2(a) and 2(b). The distribution of the particles was found uniform and at some portions clustering of Graphite and $\mathrm{SiC}$ particles was observed.

The main aim of the study is to compare the cutting force development while machining hybridised and un-hybridised composites in order to identify the effect of Graphite on the cutting force development. Dry turning test was done on both categories of materials using coated carbide tool multilayered coated carbide insert SNMG $090308 \mathrm{~K} 15$ with TiN, TiCN, $\mathrm{Al}_{2} \mathrm{O}_{3}$, and TiN coating. The specifications of the cutting tool used in the experimental work is given in the following Table 2. For each trial fresh edge of the tool insert was used to turn a length of $75 \mathrm{~mm}$. The cutting force $\left(\mathrm{F}_{X}\right)$ was measured during turning process using lathe tool dynamometer and the values were recorded and compared. The machining parameters considered for the experimentation and their corresponding levels are presented in Table 3. 


\section{Results and discussions}

The force required to shear off the material plastically from the workpiece depends on various factors such as hardness, composition and microstructure of the material to be machined, type and material of the cutting tool used, heat generated during machining and machining parameters. Experiment was done to determine the cutting force developed during machining process by considering three cutting parameters such as speed, feed and DOC. For each trial, the cutting force was measured by keeping any two parameters as constant and third parameter was varied. Experiment was carried out both on hybridised and unhybridised composites and graphs were plotted and compared to determine the effect of graphite on cutting force.

\subsection{Effect of depth of cut on cutting force}

Figures 3(a), (b), and (c) show the variation of cutting force with DOC for constant feed rate of $0.05 \mathrm{~m} / \mathrm{rev}$ and cutting speeds of $95 \mathrm{~m} / \mathrm{min}, 125 \mathrm{~m} / \mathrm{min}$ and $175 \mathrm{~m} / \mathrm{min}$ respectively for both hybridised (HC) and un-hybridised (UHC) composites. The graph clearly indicates the increasing trend with increase in depth of cut. Similar machining tests were done on fabricated composite specimen keeping feed constant and varying cutting speed at three different levels as mentioned earlier. In all the cases of experimentation, upon increase in the depth of cut, increased cutting force is noticed. Same trend is noticed even for hybridized composite with higher cutting force. Approximately 30\% increase in the cutting force is noticed between two consecutive depth of cuts and nearly $20 \%$ increase in the cutting force between unhybridized and hybridized composite material. When the DOC increases, tool penetrates more into the workpiece and hence there will be more area of contact between the workpiece and tool. This results more friction between the two surfaces which causes increase in cutting force. The cutting force developed at higher depth of cut is more for hybridised composites than un-hybridised. The reason for higher cutting force for hybridized composite is, addition of graphite as a secondary reinforcement along with $\mathrm{SiC}$ which increases the hardness level of the composite [12]. Increased material hardness certainly offers high resistance for the material deformation. The presence of more reinforcement concentration packed inside the metal matrix impinges the cutting tool inturn increases the cutting force.
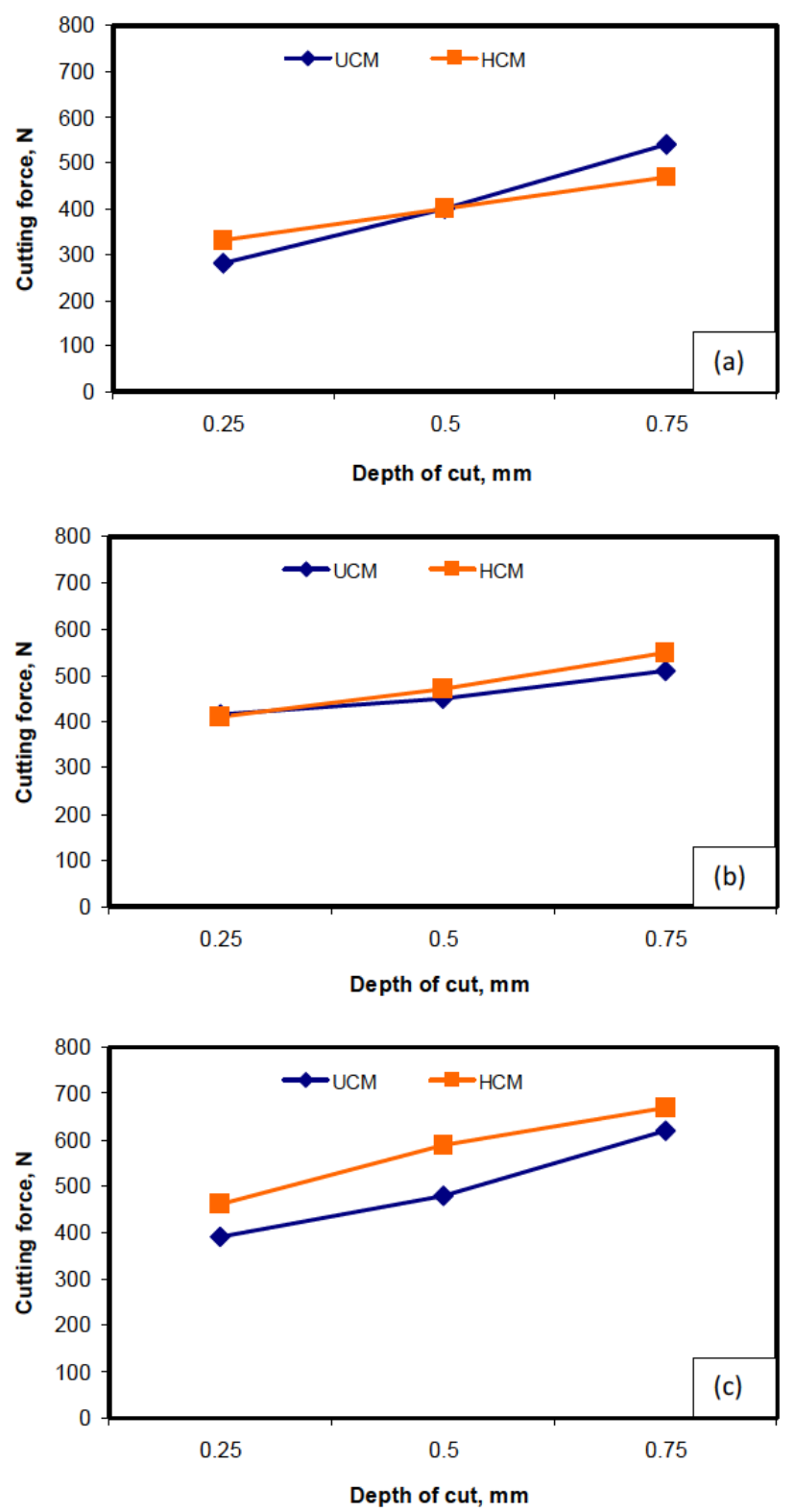

Figure 3: Variation of cutting force with depth of cut, (a) cutting speed $95 \mathrm{~m} / \mathrm{min}$, feed $0.05 \mathrm{~mm} / \mathrm{rev}$ (b) cutting speed $125 \mathrm{~m} / \mathrm{min}$, feed $0.05 \mathrm{~mm} / \mathrm{rev}$ (c) cutting speed $175 \mathrm{~m} / \mathrm{min}$, feed $0.05 \mathrm{~mm} / \mathrm{rev}$

\subsection{Effect of feed on cutting force}

During the machining process, feed rate has great influence on variation in cutting force. The machining tests were done on both the categories of materials with increasing feed viz. $0.05 \mathrm{~mm} / \mathrm{rev}, 0.1 \mathrm{~mm} / \mathrm{rev}$ and $0.15 \mathrm{~mm} / \mathrm{rev}$ respectively by keeping constant depth of cut of $0.25 \mathrm{~mm}$ and three cutting speeds as mentioned earlier. The following graphs were plotted considering recorded values of the experimental work. 

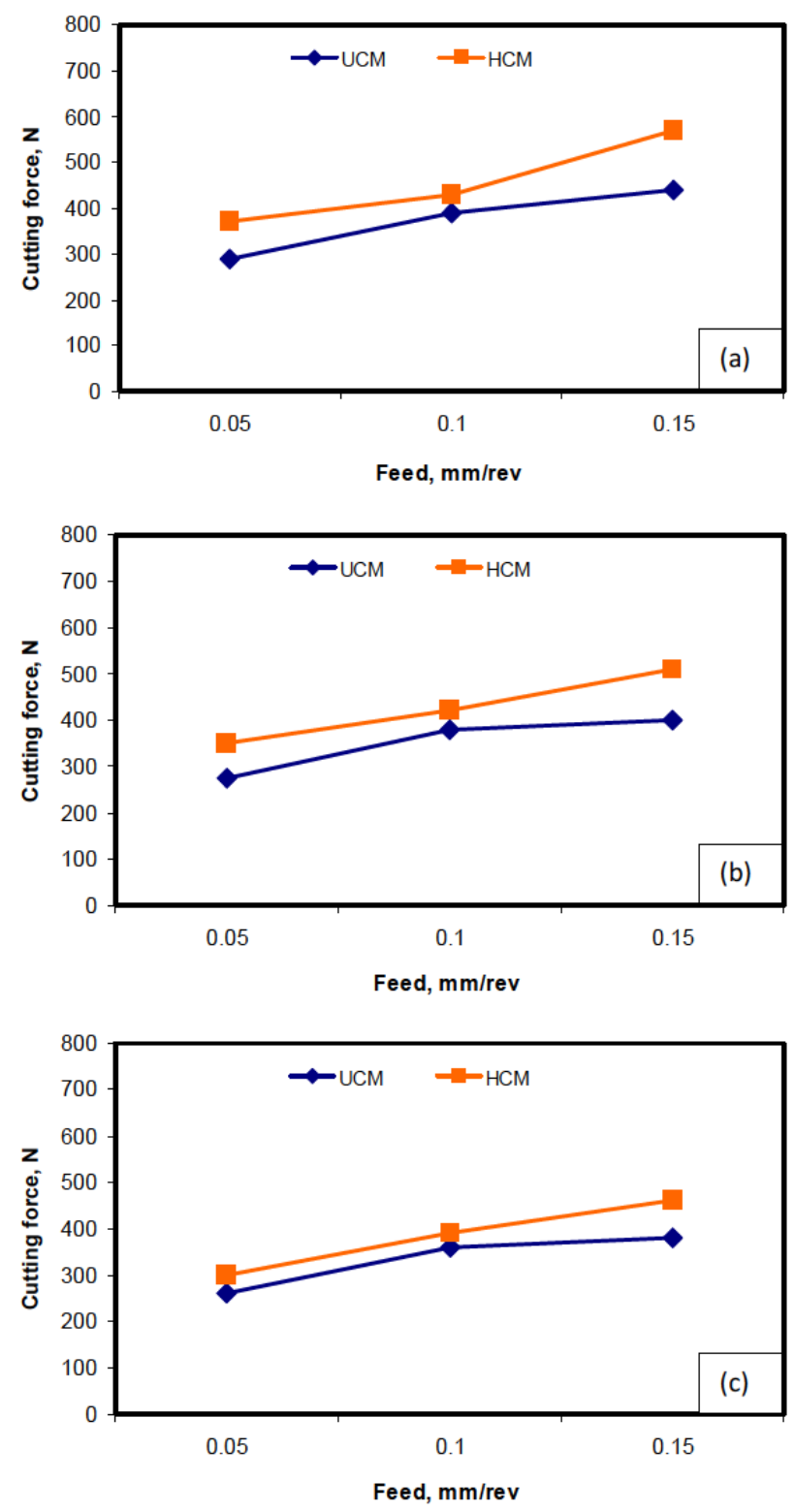

Figure 4: Variation of cutting force with increasing feed rate (a) cutting speed $95 \mathrm{~m} / \mathrm{min}$, depth of cut $0.25 \mathrm{~mm}$ (b) cutting speed 125 $\mathrm{m} / \mathrm{min}$, depth of cut $0.25 \mathrm{~mm}$ (c) cutting speed $175 \mathrm{~m} / \mathrm{min}$, depth of cut $0.25 \mathrm{~mm}$

By observing the trend, it is clear that increase in the cutting force is noticed for increase in the feed rate. For a cutting speed of $95 \mathrm{~m} / \mathrm{min}$ and constant depth of cut of $0.25 \mathrm{~mm}$ and for the feed of $0.05 \mathrm{~mm} / \mathrm{rev}$, cutting force noticed was $290 \mathrm{~N}$. When feed is increased to $0.1 \mathrm{~mm} / \mathrm{rev}$, cutting force was increased to $390 \mathrm{~N}$ and further increasing feed to $0.15 \mathrm{~mm} / \mathrm{rev}$, cutting force was increased to 440 $\mathrm{N}$. This increasing trend recorded for unhybrid composite material. With same set of machining conditions, hybrid composite specimen was turned and cutting force values were recorded. The values were $370 \mathrm{~N}, 430 \mathrm{~N}$ and $570 \mathrm{~N}$ re- spectively for $0.05 \mathrm{~mm} / \mathrm{rev}, 0.1 \mathrm{~mm} / \mathrm{rev}$ and $0.15 \mathrm{~mm} / \mathrm{rev}$ feed. Similar machining trials were executed for cutting speed of $125 \mathrm{~m} / \mathrm{min}$ and $175 \mathrm{~m} / \mathrm{min}$. In all the cases, approximately $20 \%$ to $25 \%$ increase in the cutting force values were noticed between unhybridized and hybridized composite materials. As the feed rate increases, the relative movement between the tool and workpiece along the workpiece length increases. Tool tries to advance through the hard phase of the workpiece resulting in cutting force development. The variation in the cutting force is because of hard reinforcement phase in the composite material. The hybrid composite offers higher resistance for the deformation compared to unhybrid composite. This may be due to the presence of dual reinforcement in the matrix which shows still higher resistance to the deformation compared to unhybrid composite material. Packing of reinforcements takes place in the unit mass of matrix alloy which leads to increased hardness which inturn increases the cutting force.

\subsection{Effect of cutting speed on cutting force}

To study the variation of cutting force with variation of cutting speed, both feed and depth of cut is kept constant for each set of machining trial and cutting speed is varied. All the three cutting speeds $95 \mathrm{~m} / \mathrm{min}, 125 \mathrm{~m} / \mathrm{min}$ and $175 \mathrm{~m} / \mathrm{min}$ were employed and variation is studied. Figure 5 shows the variation of cutting force for varying cutting speed.

The feed of $0.05 \mathrm{~mm} / \mathrm{rev}$ and depth of cut of $0.25 \mathrm{~mm}$ with all three cutting speeds shows declining trend of cutting force. For $95 \mathrm{~m} / \mathrm{min}, 125 \mathrm{~m} / \mathrm{min}$ and $175 \mathrm{~m} / \mathrm{min}$, the cutting force development for unhybridized composites were $290 \mathrm{~N}, 275 \mathrm{~N}, 260 \mathrm{~N}$ respectively. By observing the variation it is clear that cutting force decreases with increase in cutting speed. Same machining tests were done on hybridized composite specimen and similar declining trend was recorded. For the cutting speed of $95 \mathrm{~m} / \mathrm{min}$, $125 \mathrm{~m} / \mathrm{min}$ and $175 \mathrm{~m} / \mathrm{min}$, the cutting force developed was $370 \mathrm{~N}, 350 \mathrm{~N}, 300 \mathrm{~N}$ for hybridized composite respectively. Approximately $25 \%$ to $30 \%$ variation in the cutting force was noticed between hybridized and unhybridized composite material machining. Similar experimental trials were done by varying feed and results were recorded. The declining trend may be due to the fact that the rise in temperature while machining the composite increases with the increase in cutting speed. At elevated temperature levels, the matrix phase becomes soft, hence the force required to cut the metal will be less. It can also be observed from the graph that the cutting force developed for hy- 

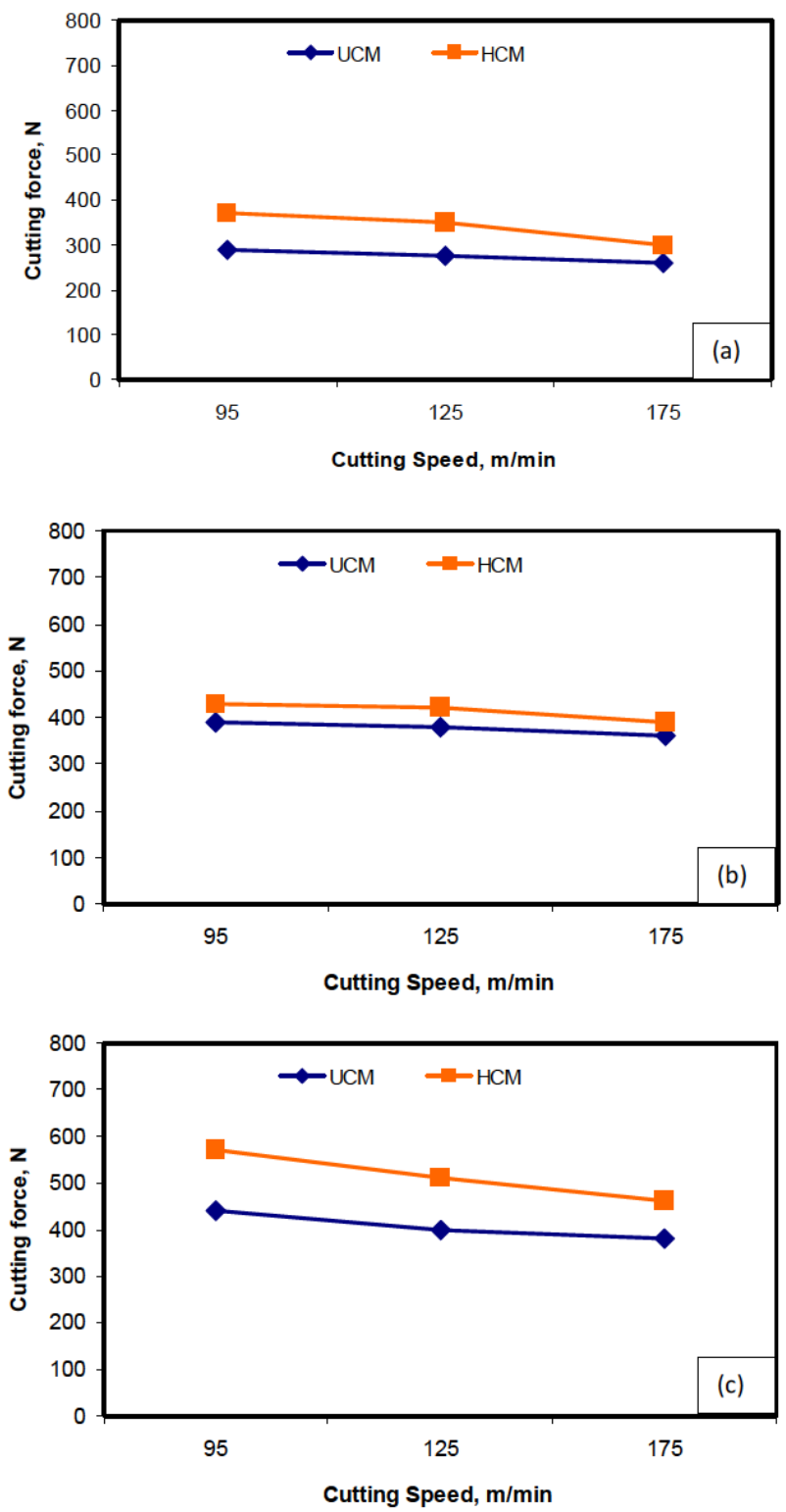

Figure 5: Variation of cutting force with increasing cutting speed (a) feed $0.05 \mathrm{~mm} / \mathrm{rev}$, depth of cut $0.25 \mathrm{~mm}$ (b) feed $0.1 \mathrm{~mm} / \mathrm{rev}$, depth of cut $0.25 \mathrm{~mm}$ (c) feed $0.15 \mathrm{~mm} / \mathrm{rev}$, depth of cut $0.25 \mathrm{~mm}$

bridised composite is more compared to the un-hybridised composite. This may be due to the increased friction during machining process leading to higher temperature development. As cutting temperature increases, the force required to deform the material decreases. The hybridized composite develops higher cutting force at lower temperature and lower cutting force at higher temperature. The presence of graphite in the matrix may reduce the tool wear during the machining process where as it increases the cutting force.

\section{Conclusions}

The present paper deals with fabrication of hybridized and un-hybridized composites i.e. ZA43 alloy reinforced SiC particulate composite and ZA43 alloy reinforced SiC and graphite composites. Both the categories of materials were machined with coated carbide tool under selected set of machining conditions. While machining, the cutting force was measured using three axis lathe tool dynamometer. Forces developed are compared and conclusions are drawn as follows.

1. The depth of cut has direct effect on the cutting force development. As depth of cut is increased, cutting force increases correspondingly. The cutting force developed during machining of hybridized composite was higher compared to un-hybridized composites for a particular depth of cut.

2. The variation of feed during machining has direct impact on the cutting force. The value of the cutting force increases with the increase in feed rate. The cutting force developed during the machining of hybridized composite was higher than as obtained during the machining of un-hybridized composite for the same feed.

3. The cutting speed affects the cutting force in declining way. For both the types of composites, the cutting force developed during the machining tends to decrease with the increase in cutting speed. The development of higher cutting force was observed for hybridized composite over the un-hybridized composite.

4. By observing and analysing all the results obtained during the machining of both the types of composites, it was obvious that the addition of graphite into the matrix phase as the secondary reinforcing element increases the cutting force for all the experiments conducted.

\section{References}

[1] Das S., Development of aluminium alloy composite for engineering applications Trans. Ind. Instit. Mater., 2004, 27 (4), 325-334.

[2] Umakanth K., Palani Kumar K., Selvamani S.T., Analysis of dry sliding wear behaviour of Al6061/Sic/Al203 hybrid metal matrix composites, Compos. Eng. Part B, 2013, 53, 159-168.

[3] James S.J., Venkatesan K., Kuppan P., Ramanujam R., Hybrid aluminium metal matrix composite reinforced with $\mathrm{SiC}$ and $\mathrm{TiB}_{2}$, Proc. Eng., 2014, 97, 1018-1026.

[4] Davim J.P., Bapista A.M., Relationship between cutting force and $P C D$ cutting tool wear in machining silicon carbide reinforced 
aluminium, J. Material Proc. Technol., 2000, 103, 417-423.

[5] Kannan S., Kishawy H.A., Brunswick N., On the role of reinforcements on tool performance during cutting of metal matrix composites, J. Manuf. Proc., 2006, 8(2), 67-71.

[6] Ozben T., Kilickap E., Orhan C., Investigation of mechanical and machinability properties of SiC particle reinforced Al-MMC, J. Mater. Proc. Technol., 2007, 8, 220-225.

[7] Marigoudar R.N., Kanakuppi S., Investigation of tool wear and surface roughness during machining of ZA43-SiCp composite suing full factorial approach, J. Eng. Manuf., 2013, 27, 321-331.

[8] Aydin M., High cycle fatigue behaviour of severe plastically deformed binary $\mathrm{Zn}-60 \mathrm{Al}$ alloy by equal-channel angular extrusion, J. Mater. Proc. Technol., 2012, 212(8), 1780-1789.

[9] Ares E., Schvezov C.E., The effect of structure on tensile properties of directionally solidified Zn-based alloys, J. Cryst. Growth, 2011, 318(1), 56-65.

[10] Zhu Y.H., Biao Y., Wei H., Bearing wear resistance of monotectoid Zn-Al based alloy (ZA-35), J. Mater. Sci. Technol., 1995, 11, 109113

[11] Purcek G., Saray O., Kucukomeroglu T., Haouaoui M., Karaman I., Effect of equal-channel angular extrusion on the mechanical and tribological properties of as cast $\mathrm{Zn}-40 \mathrm{Al}-2 \mathrm{Cu}-2 \mathrm{Si}$ alloy, Mater. Sci. Eng. A, 2010, 527(15), 3480-3488.

[12] Basavarajappa S., Chandramohan G., Rao K.V.N., Turning of particulate metal matrix composite-review and discussion, Proc. Inst. Mech. Eng., Part B: J Eng. Manuf., 2006, 220, 1189-1204.

[13] Anandkrishnan V., Mahamani A., Investigations of flank wear, cutting force and surface roughness in the machining of Al-6061$\mathrm{TiB}_{2}$ in situ metal matrix composites produced by flux assisted synthesis, Int. J. Adv. Manuf. Technol., 2010, 55 (1-4), 65-73.

[14] Davim J.P., Anto A., Conceic C.A., Optimal cutting conditions in turning of particulate metal matrix composites based on experiment and genetic search model, Compos. Part A, 2002, 33, 213-219.

[15] Davim J.P., Turning metal matrix composites: Experimental study of the evaluation of cutting forces, tool wear and work piece surface roughness with the cutting time, Proc. Instit. Mech. Eng., Part B: J. Eng. Manuf., 2001, 215B, 371-376.
[16] Manna A., Battacharya B., Influence of machining parameters on the machinability of particulate reinforced Al/SiC-MMC, Int. J. Adv. Manuf. Technol., 2004, 25, 850-856.

[17] Manna A., Battacharya B., A study on machinability of Al/SiCMMC, J. Adv. Manuf. Technol., 2003, 140, 711-716.

[18] Chou Y.R.K., Liu J., CVD diamond tool performance in metal matrix composite machining, Surf. Coat. Technol., 2005, 200, 18721878.

[19] Kannan S., Kishwy H. A., Deiab I., Cutting forces and TEM analysis of the generated surface, J. Mater. Process. Technol., 2008, 9, 2260-2269.

[20] Zhu Y., Kishwy H.A., Influence of the alumina particles on the mechanics of machining metal matrix composites, Int. J. Mach. Tool Manuf., 2005, 45, 389-398.

[21] Marigoudar R.N., Kanakuppi S., Analysis of cutting forces developed during turning of SiC reinforced ZA43 mmc with ceramic tool using design of experiments, J. Manuf. Sci. Prod., 2012, 12, 129-137.

[22] Dabade U.A., Dapkekar D., Joshi S.S., Modelling of chip-tool interface friction to predict cutting forces in machining of $\mathrm{Al} / \mathrm{SiC}$ composites, Int. J. Mach. Tool Manuf., 2009, 49, 690-700.

[23] Dabade U.A., Joshi S.S., Balasubramaniam R., Bhanuprasad V.V., Surface finish and integrity of machined surfaces on $\mathrm{Al} / \mathrm{SiC}$ composites, J. Mater. Process. Technol., 2007, 193, 166-174.

[24] Pramanik L., Zhang C.A., Arsecularatne J.A., Machining of metal matrix composites: Effect of ceramic particles on residual stress, surface roughness and chip formation, Int. J. Mach. Tool Manuf., 2008, 48, 1613-1625.

[25] Sikder S., Kishwy H.A., Analytical model for force prediction when machining metal matrix composite, Int. J. Mech. Sci., 2012, 59, 95-103.

[26] Lim S.C., Gupta M., Ren L., Kwok J.K.M., The tribological properties of $\mathrm{Al}+\mathrm{Cu} / \mathrm{SiC}$ metal matrix composites fabricated using the rheocasting technique, J. Mater. Process. Technol., 1991, 90, 591-596.

[27] Hashim J., Looney L., Hashmi M.S.J., Wettability of SiC particles by molten aluminium alloy, J. Mater. Process. Technol., 2001, 119, 324-328. 